\title{
ON THE TACHINID GENUS ACROGLOSSA WILLIS'TON.
}

BY D. W. COQUILlETT, WASHINGTON, D. C.

A short time ago, in the course of classifying the Tachinidae in my collection, I referred one of the species to Acroglossa hesperidarum Will., since it agreed in every particular with the description of this genus and species in Scudder's "Butterflies of New England" pp. I9I6-I9I7, with the single exception that the anterior pair of ocellar bristles curved backward, instead of forward, as stated in the descriptiona discrepancy which I imputed to a typographical or clerical error. The species also agreed so well with the descriptions of the genus Spallanzania Desv. as given by various European authors that $\mathrm{I}$ accepted the statement of Brauer and Bergenstamm, based upon a study of North and South American specimens, that the genus Acroglossa Williston is identicil with the previously described Spallanzania Desvoidy (not Rondani, to whom these authors erroneously credit it; $Z$ weif. Kais. Museums Wien, V, 354). Nut long after this I received a copy of a paper by Giglio-Tos, on the "Ditteri del Messico, parte III," wherein this author refers a Mexican species to Acroglossa (1. c., 35), stating that the latter genus canno be the same as Spallanzania, owing to the fact that the ocellar bristles curve forward - an opinion reiterated by Mr. W. A. Snow in the Kans. Univ. Quarterly, III, I85.
Neither of these authors had seen the types of Acroglossa, which are contained in the Harris collection, now in the Boston Museum. Wishing to settle this matter definitely I applied to the Secretary, Mr. Samuel Henshaw, who kindly examined these types for me and writes that the bristles/in question curve backward. My supposition of an error in the original description, therefore, proves to be correct, and there is no valid reason for not sinking Acroglossa as a synonym of Spallanzania.

It is interesting to note that $\mathrm{Mr}$. C. H. T. Townsend had correctly identified a specimen of Acroglossa hesperidarum. Mr. W. A. Snow recently compared this specimen "ith the types of Pseudogonia ruficauda Town. and $P$. obsoleta Towns., and reached the conclusion that they all belong to one and the same species (1. c, I 84). The descriptions leave no doubt that this is the true Acroglossa hesperidarum Will.

Brauer and Bergenstamm refer Cnephalia Rond., Pseudogonia B. B. and Spallanzania Desv. as sub-gunera of one genus, to which they erroneously apply the name of Cnephalia (1. c., VI, 2.4); whereas Spallanzania is much the older name. Owing to the fact that in certain species of this genus the third antennal and second aristal 
joints vary in the different specimens of the same species even to a greater degree than the above authors state exists between Cnephalia and Spallanzania, the former cannot be maintained even in the sense of a sub-genus, but must be considered a synonym of Spallanzania.

The species referred to above as having been assigned to Acroglossa by Giglio-Tos, is evidently the form previously described by Van der Wulp as Prospherysa vilis (Biol. Cent. Am., Diptera, II, I2I), which Brauer and Bergenstamm make the type of their new genus, Chaetogaedia (1. c., V, 336). Giglio Tos remarks on the close resemblance between his species and Frontina acroglossoides Town.,; the latter is a synonym of Baumhaueria analis $\mathrm{V}$. d. W., and also belongs to Chaetogaedia.

The forms discussed above may be listed as follows (synonyms in italics) : Spallanzania Desv. Cnephalia Rond.; Acroglossa Will.

hesperidarum Will. (Acroglossa). Pseudogonia ruficauda Town.; $P$. obsoleta Town.

Chaetogaedia B. B. analis V. d. W. (Baumhaueria). Frontina acroglossoides Town. vilis V. d. W. (Prospherysa) Acroglossa tessellata Giglio-Tos.

\section{WOOLLY LEAF-GALL MADE BY A SPECIES OF CALLIRHYTIS (ON SCRUB OAK.}

BY C. H. TYLER TOWNSEND, BROWNSVILLE, TEX.

In the Can. Ent., I\$92, p. 200, I mentioned the breeding of a hymenopteron, determined by Dr. Riley as Andricus sp. (?) from a woolly leafgrall on scrub oak, found in the Organ Mts., Donna Ana Co., N. M.

On Nov. 12, 1892, this gall was found on scrub oak well up in the Organ Mts., above the Modoc vine. Sections that were opened on this date contained pupae. The galls were also noticed same date on scrub oaks at the base of the same mountains, at Riley's water.

On March 16, I893, there were found issued and dead, from galls collected
Nov. 12, I892, eleven gall-flies of a beautiful metallic green color. This is the above species. There was also found one specimen, larger in size and of a flavous brown color, apparently different, which had issued with the rest.

The gall may be described as follows :-

Ciall.-Diameter, about $\mathrm{I}_{2}$ to $\mathrm{I}_{5} \mathrm{~mm}$; greatest height, 8 to $9 \mathrm{~mm}$. On under side of leaf, woolly subhemispherical or domeshaped in form, attached to the leaf by small rootlets or stems on the basal flattened surface, a stem to each principal section of the gall. Color, pink externally, shaded to slightly brownish or yellowish in mature or 

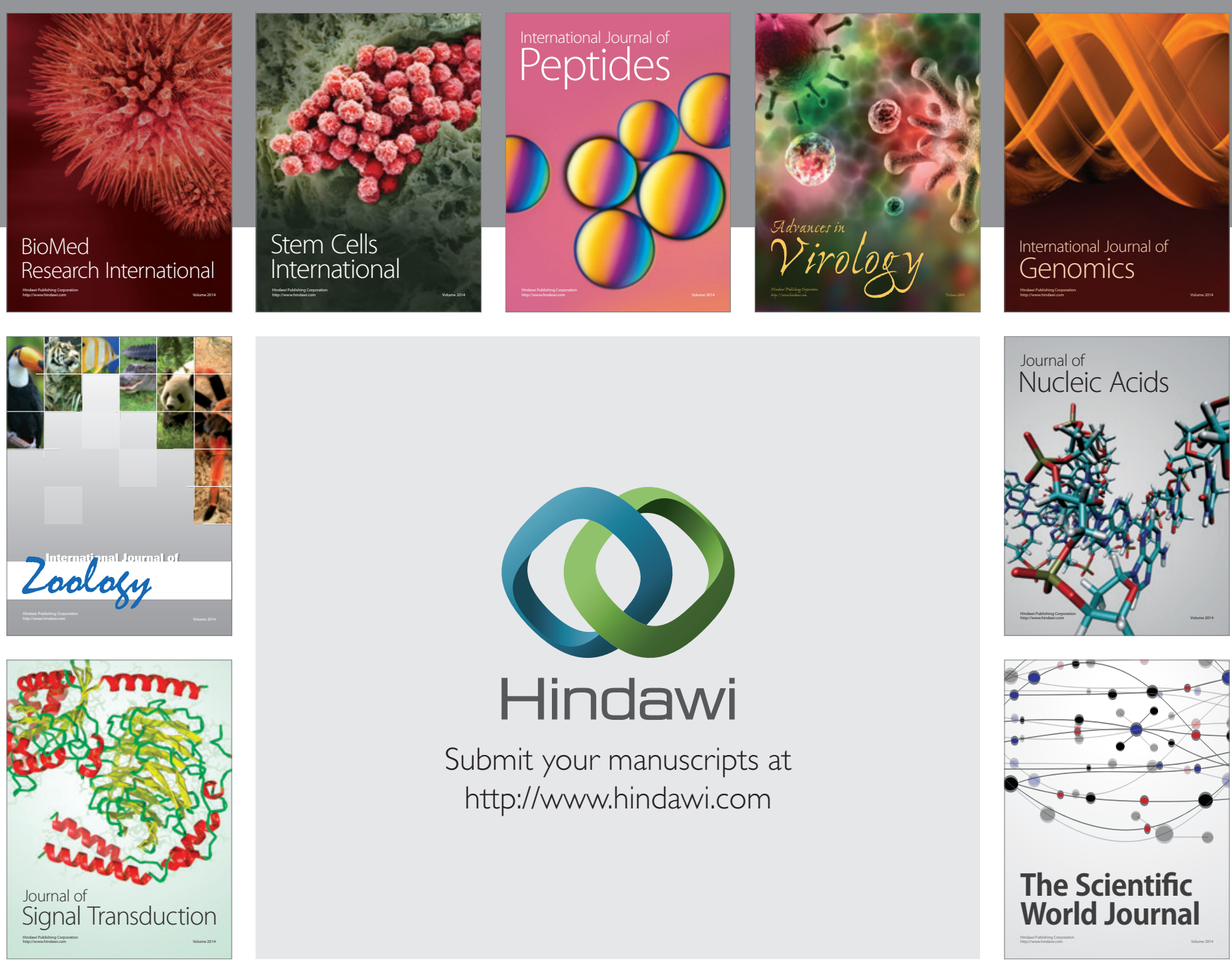

Submit your manuscripts at

http://www.hindawi.com
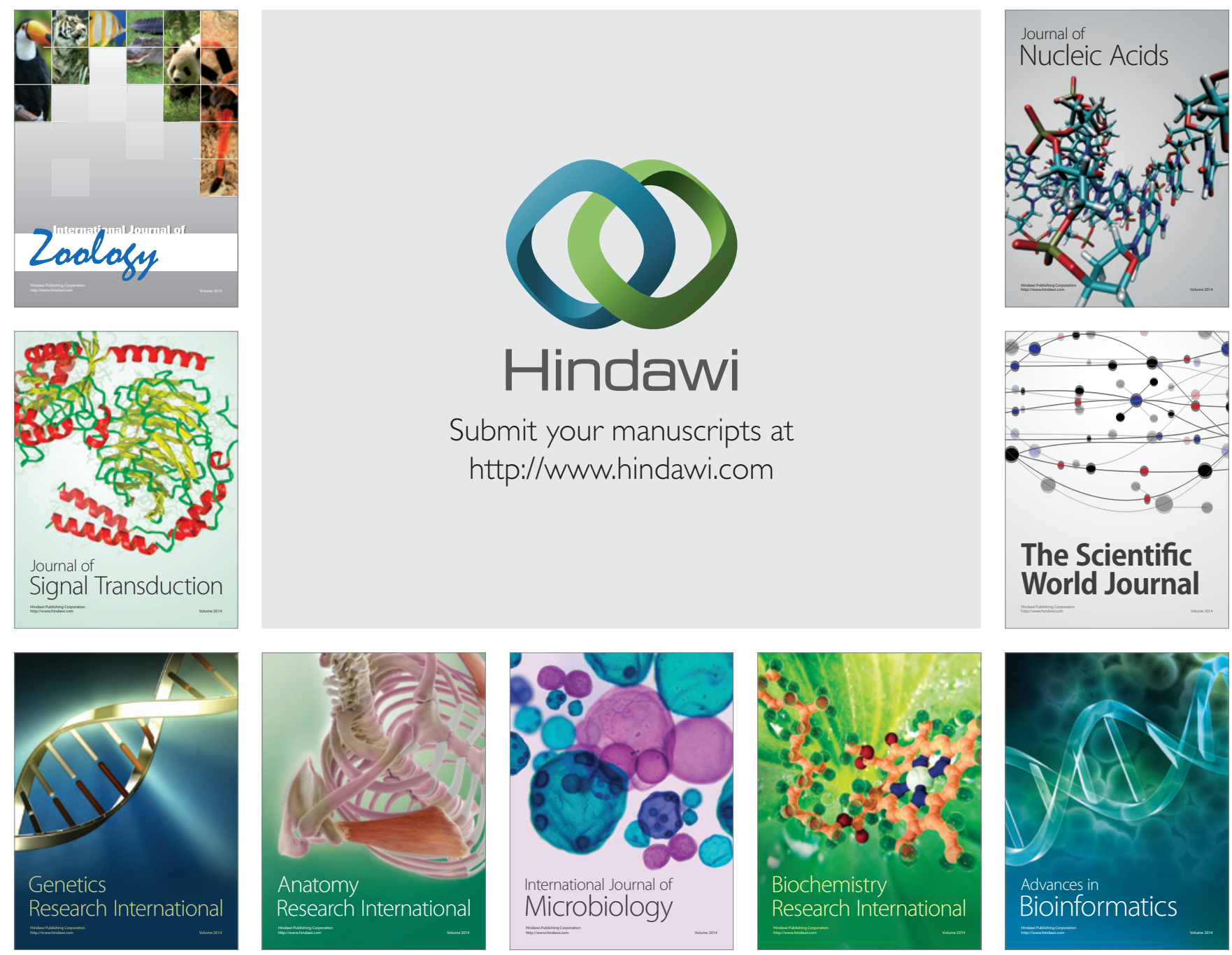

The Scientific World Journal
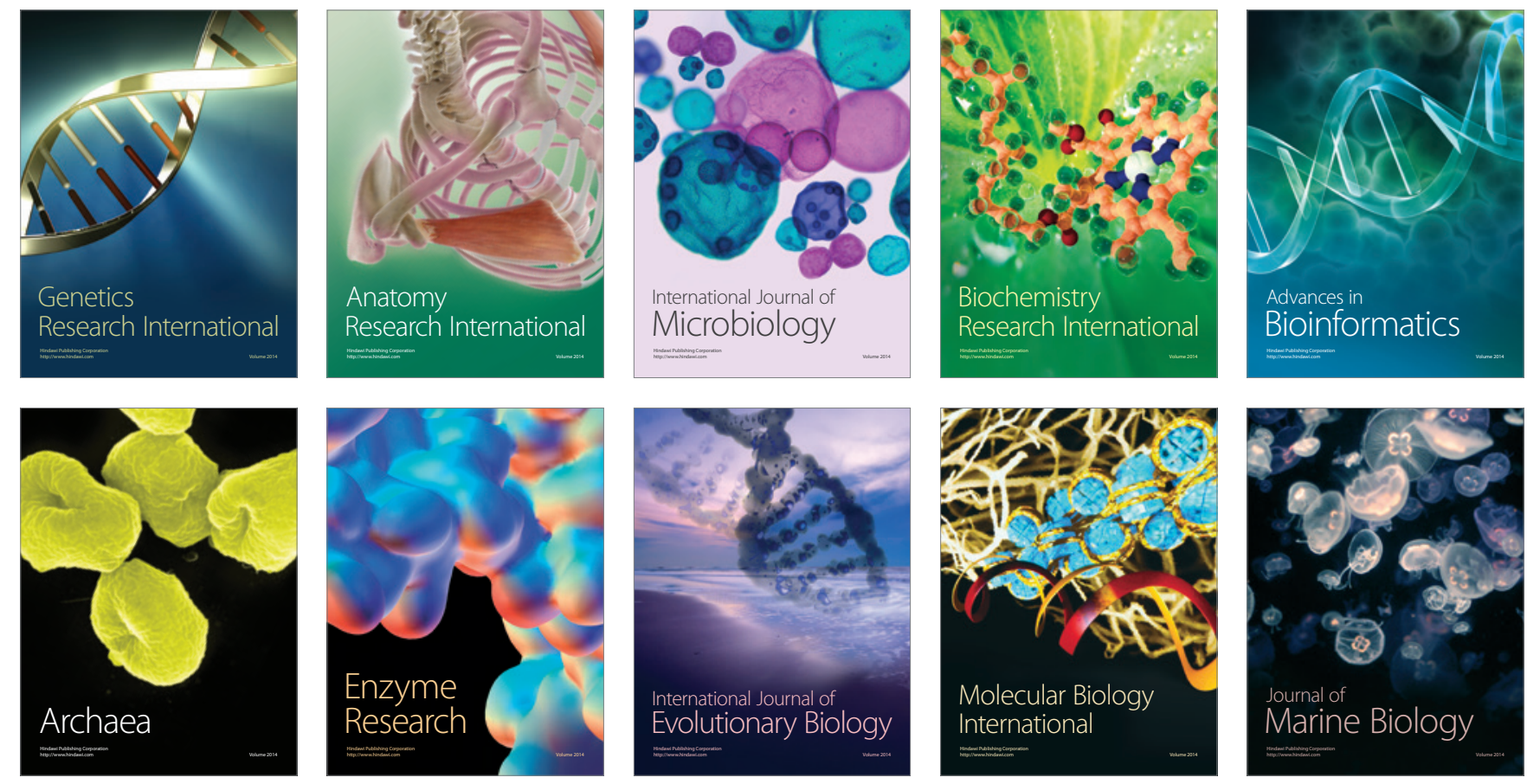